\title{
A Case Study of Coordinated Electric Vehicle Charging for Peak Shaving on a Low Voltage Grid
}

\author{
N. Leemput, Graduate Student Member, IEEE, F. Geth, Graduate Student Member, IEEE, B. Claessens, \\ J. Van Roy, Graduate Student Member, IEEE, R. Ponnette and J. Driesen, Senior Member, IEEE
}

\begin{abstract}
This paper discusses the impact of coordinated charging of electric vehicles for a peak shaving objective, through an online coordination algorithm, on low voltage grid constraints. The results for uncoordinated and coordinated charging are compared to assess the effect on the peak power demand. Furthermore, an unbalanced load flow analysis is performed on a real low voltage grid to assess the impact on the nodal voltages. The simulation results show a positive impact of coordinated charging for both the peak shaving objective and for voltage deviations. The results show that the coordination algorithm obtains effective results, while only needing a limited amount of communication, measurements and predictive knowledge.
\end{abstract}

Index Terms--Coordinated charging; Electric vehicles; Smart
grids

\section{INTRODUCTION}

$\mathrm{T}$ HERE is a new wave of electric vehicles (EVs) being introduced into the market in the near-term future [1]. The application of electricity for propulsion offers opportunities to reduce the consumption of greenhouse gas emitting fuels such as gasoline and diesel [2], [3]. Additionally, the local concentrations of pollutants harmful to human health are reduced, due to the absence of tailpipe emissions [4].

Before driving, EVs are charged with energy supplied through the power system. The increasing EV fleet size will have an impact on the power system in terms of total energy consumption, changing of load patterns, etc. It is generally concluded that uncoordinated charging of EVs will significantly decrease the grid voltage because of the simultaneity between the household load peak and the plugging in of the vehicle to start charging, when arriving at home [5]. The coordination of the charging EVs may avoid grid problems in such situations, while considering the primary objective of the EVs, namely providing a mobility service.

The work is supported by the Flemish Government through the LINEAR project (IWT/090800) organized by the Institute for Science and Technology (IWT). N. Leemput has a Ph.D. grant of the Institute for the Promotion of Innovation through Science and Technology in Flanders (IWT-Vlaanderen).

Niels Leemput, Frederik Geth, Juan Van Roy and Johan Driesen are with the Department of Electrical Engineering (ESAT), Division ELECTA, KU Leuven, Kasteelpark Arenberg 10, bus 2445, 3001 Leuven-Heverlee, Belgium (e-mail: niels.leemput@esat.kuleuven.be).

Bert Claessens and Raf Ponnette are with VITO, Boeretang 200, 2400 Mol, Belgium. ).

KU Leuven and VITO are partners of Energyville, Dennenstraat 7, 3600 Genk, Belgium.

\section{A. Coordinated Charging}

Within the EV work package of the LINEAR project [6], a literature on coordination strategies was performed [7]. This study establishes that a significant amount of research has already been performed on coordinated charging of EVs. Charging coordination strategies can reduce the impact on the power system, by making more efficient use of the capacity in the system [8]. Typically, the proposed coordination strategies optimize the charging behavior for objectives such as minimal charging cost, valley filling, peak shaving, etc.

Coordination may not interfere with the mobility objective of EVs. Typically, mobility behavior offers flexibility towards the charging of the $\mathrm{EV}$, due to long vehicle standstill times (on average above $90 \%$ in Belgium) and relatively low distances driven (41 km/day on average in Belgium) [9]. The EV users determine the flexibility, by indicating the departure time of next trip and required range. An additional objective such as peak shaving can be used to determine a unique charging pattern.

\section{B. Coordination for Peak Shaving}

EV charging has an influence on the peak power demand of the distribution system [8], [11] as well as on the harmonic content of the gird power, because chargers are power electronic grid-connected devices. Therefore, the impact of coordination on the technical lifetime of the distribution system assets, e.g. transformers and cables [12], [13], must be analyzed. The exploitation costs of the distribution system may increase if the technical lifetime of the assets is reduced below the economic and strategic lifetime.

For transformers, thermal effects significantly influence the technical lifetime through the accelerated aging of the insulation. Therefore, IEEE C57-110-2008 standard is developed to determine the capability of a transformer for non-sinusoidal currents based on a current harmonics spectrum and the rated per unit loss density of the winding hot spot [14]. Aging is considered an exponential function of the hot spot temperature, which in turn depends on the currents flowing through the transformer. Therefore, an increase in peak loading, due to uncoordinated EV charging, has a significant influence on aging of transformers that are already operating close to their limits [13], [15].

For cables, different models and theories exist for lifetime estimation. As discussed in [16], none of the most often used is known to yield reliable life predictions. However, the aging of the insulation due to thermal stresses is also considered as a 
significant parameter for cables [16], [17]. Therefore, peak shaving can also be considered beneficial for cable aging.

As discussed in [18], IEEE C57-110-2008 is a conservative estimate of transformer loading capability, because dynamic variation of transformer load and ambient temperature are not considered. Therefore, it is suggested to use dynamic loading capability to load a transformer beyond conventional limits [18]. Furthermore, abnormal events like overvoltage and system faults cause more transformer failures than aging of winding isolation [19]. Transformers at age are more vulnerable to such events.

Furthermore, load shifting, that is the result of the peak shaving objective for EV charging, will flatten out the load profile of the transformer [13]. This reduces the daily thermal expansion and contraction of the transformer, thus reducing mechanical stresses on the components. This could decrease the probability of transformer failing, as discussed in [13].

Finally, coordinated EV charging could reduce net injection of photovoltaic (PV) power production from the LV into the medium voltage grid, by using this energy to charge the EVs. Reverse energy flows have a significant influence on transformer aging, due to the higher voltages that occur. At higher voltages, iron losses increase substantially, which increases in turn the thermal stresses.

\section{Voltages}

As discussed in the previous subsection, a peak shaving coordination strategy seems to be beneficial for the distribution system assets. Therefore, it can be considered as a useful coordination objective for a constrained grid, where uncoordinated charging would lead to asset overloading. However, a peak shaving coordination strategy will also influence other parameters of the power system, such as the nodal voltages at the LV distribution grid where the vehicles are located and charged.

Nodal voltages are subject to regulation. The European EN50160 standard specifies that the 10 -minute mean rms voltage deviation should not exceed $\pm 10 \%$ of the nominal voltage. In the test procedure, a wider range is allowed for under voltage: $-15 \%$ to $-10 \%$ for $5 \%$ of the time per week [21]. Additionally, the 10-minute mean rms value of the voltage unbalance factor (VUF) should be below $2 \%$ for $95 \%$ of time, measured on a weekly base [20].

DSOs take such constraints into account in their asset planning. Load flow analyses are performed, using assumption and predictions of the local loads [21], often based on historical data. Voltage subject to regulation should stay within limits, with a significant margin to take into account future load increase [21]. In this sense, distribution system planning is a feed-forward strategy without feedback on the operational level.
Consequently, operational philosophy is to stay away from the limits as far as possible. Therefore, it is essential that EV coordination for transformer peak shaving does not increase the voltage deviations, relative to the uncoordinated charging scenario. Otherwise, the initial target of the coordination, namely avoiding transformer upgrading, would be counteracted by a new need for cable upgrading.

\section{Scope}

The scope of this paper is to assess the impact of an online coordination strategy for peak shaving on the LV grid. Therefore, uncoordinated and coordinated EV charging are compared. Coordinated charging is implemented with an online multi-agent market based demand side management algorithm (Intelligator) that uses a limited amount of predictive knowledge [22].

\section{SCENARIO}

\section{A. Grid}

For the load flow analysis, real grid topologies are used, combined with real household load profiles. This information is provided by Flemish DSOs, partners within the LINEAR project. A LV residential grid $(400 / 230 \mathrm{~V})$, sometimes operating close to its technical limits, is considered. The grid topology is illustrated in Fig. 1. The topology is that of a real suburban feeder with a TT grounding arrangement located in Flanders, Belgium. All households are assumed to have a single-phase grid connection between one of the three phases and the common neutral conductor.

Cable parameters are taken from the design specifications of the standard for underground distribution cables, NBN C33322 [23]. Cable type EAXVB $1 \mathrm{kV} 4 \times 150 \mathrm{~mm}^{2}$ is used for the main feeder, with exception of the segment between nodes 2 and 4. For this segment, type EAXVB $1 \mathrm{kV} 4 \times 95 \mathrm{~mm}^{2}$ is used. Cable type EXVB $1 \mathrm{kV} 4 \times 16 \mathrm{~mm}^{2}$ is used to connect the household supply terminals with the main feeder. These cables are between 10 and $25 \mathrm{~m}$ in length.

\section{B. Loads and Generation}

In the LINEAR project [6], 62 household electricity consumption profiles were measured on a fifteen-minute basis, at households statistically representative for Flanders. Reactive power consumption was not measured and is therefore neglected in simulation.

In the distribution grid, 30 houses are assigned a PV installation. The PV profile for these installations is measured on a 15-minute base at an installation of KU Leuven. The simulation is performed for the year 2007 with a 15 -minute time step, the time resolution of the load and production profiles. The PV profile is scaled, to match the annual

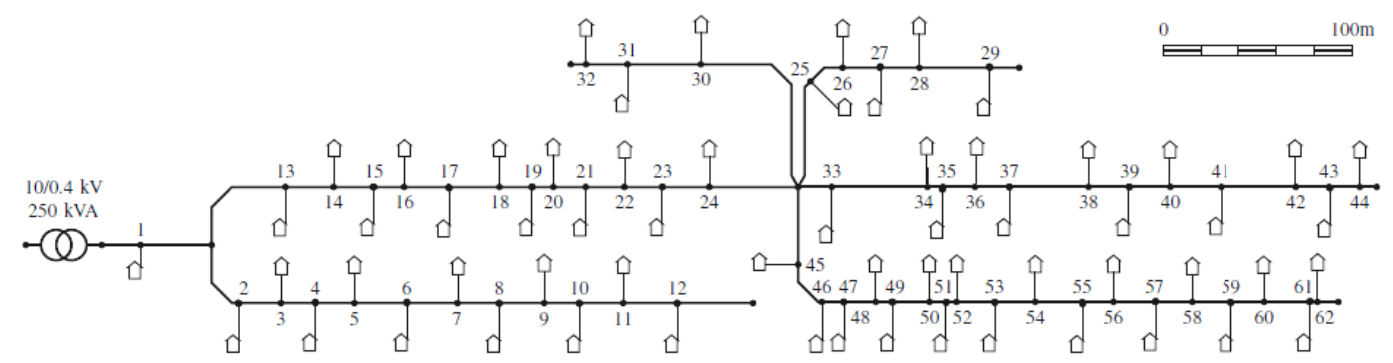

Fig. 1. Distribution grid topology used in the simulations. Cable lengths are drawn to scale. 
generation to the household load at the selected locations, considering a range of commercially available panel and single-phase inverter sizes and a maximum of $5 \mathrm{kVA}$ imposed by regulations [24].

The EV charging profiles, 30 for this scenario, are based on Flemish mobility behavior and are generated on a 15 -minute base [9]. A specific energy consumption of $200 \mathrm{Wh} / \mathrm{km}$ and a usable battery capacity of $20 \mathrm{kWh}$ are chosen. For the EVs, it is assumed that they will only charge at home. Two EV charging scenarios will be simulated: uncoordinated and coordinated charging. For the case of uncoordinated charging, vehicles will immediately start charging when they arrive at home, until their battery is completely recharged. In the second case, charging will be coordinated to avoid an increase in transformer peak loading.

The load and generation statistics are illustrated in Fig. 2. The first column (Phase) indicates at which phase each node is connected. The following three columns illustrate household energy consumption (Energy HH), PV energy production (Energy PV) and EV energy consumption (Energy EV). These results remain the same for each of the scenarios; they are independent on how the EVs are charged.

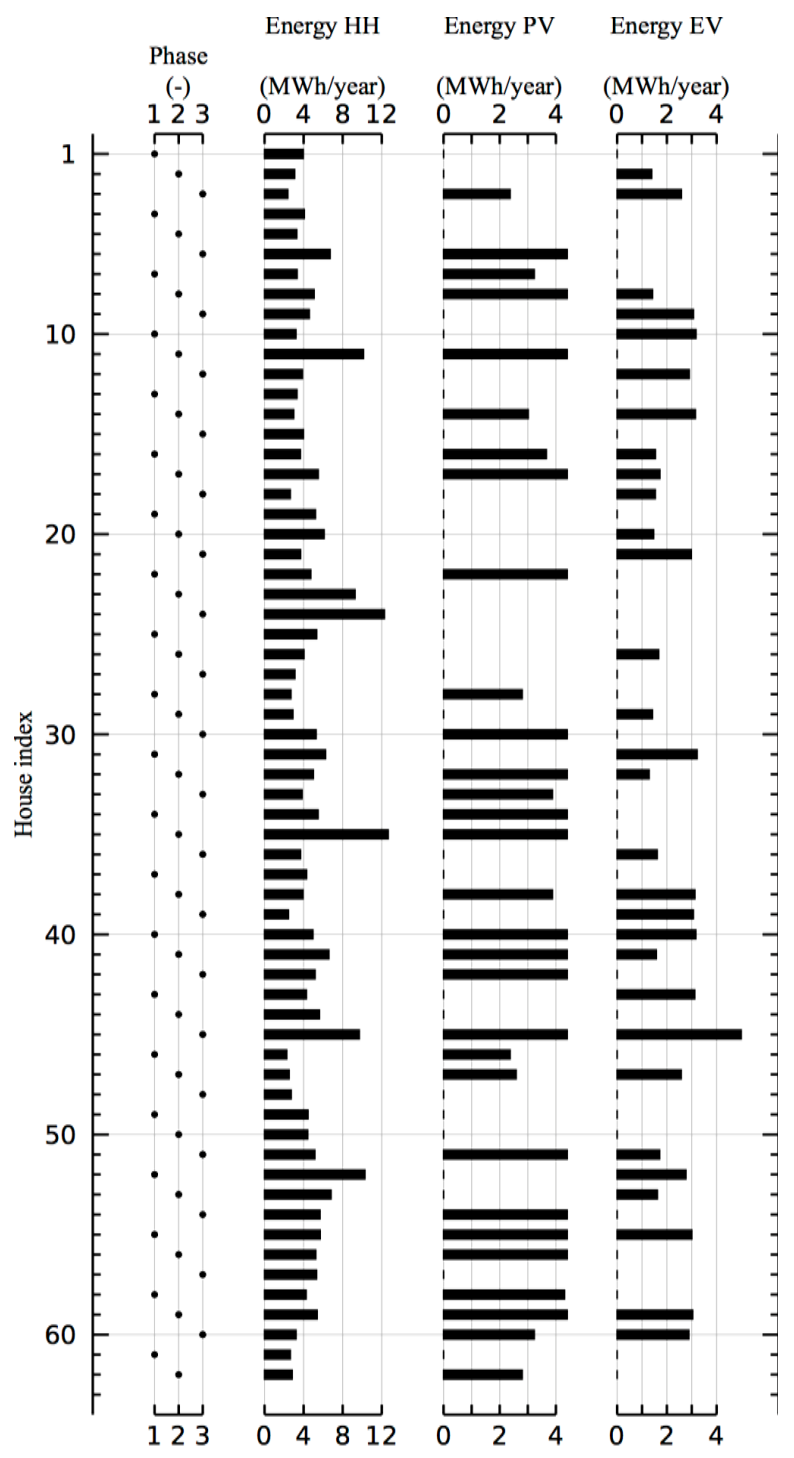

Fig. 2. Load and generation statistics.

\section{Grid Impact Analysis}

For uncoordinated charging, the impact on the grid is investigated. The impact of the EVs on the load duration curve for uncoordinated charging is illustrated in Fig. 3. Without coordination, charging starts when vehicles arrive at home, which increases peak power demand especially in the evening due to the correlation between arrivals at home and vehicles being plugged in and the rising household consumption. The negative values in power consumption are due to PV power production exceeding household and EV energy consumption.
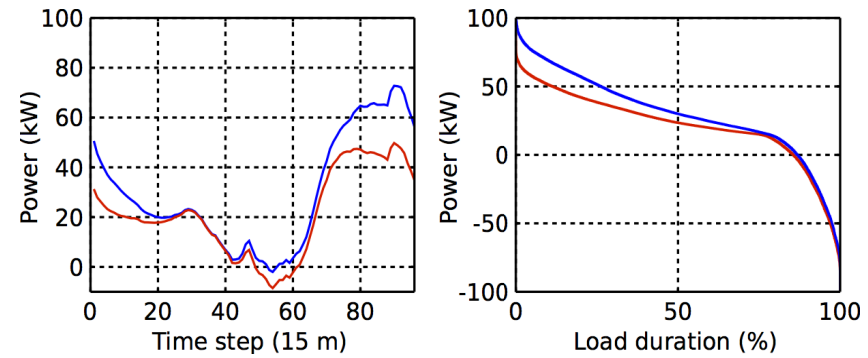

Fig. 3. Daily average transformer load profile (left) and annual load duration curve (right) for the scenario without EVs (red) and with uncoordinated (blue) EV charging.

Because of the mobility behavior of the EVs, there is a weak correlation between EV charging and PV power production. At the moment the PV installations are producing power, most vehicles are not charging, because they are not located at home or they are already fully charged. Therefore, the presence of $\mathrm{PV}$ installations does not significantly influences peak power demand increase due to EVs. If peak power demand increases above the transformer rating, the technical lifetime will be significantly reduced.

For the nodal grid parameters, nodal voltages and unbalance factors, a three-phase unbalanced load flow analysis, implemented in MATLAB, is used. Therefore, voltage deviations due to the unbalanced load situation are taken into account, as well as the zero-point shifting due to the currents that run through the common neutral conductor. Because of the radial grid topology, the backward-forward sweep technique is used [5]. All loads are modeled as a constant power load.

A modified box plot is used to display the distribution of time profiles, in which the inner box spans the 25th to 75th percentiles. The outer box spans the 5th to 95th percentiles and the whiskers extend to the minimum and maximum values, as illustrated in Fig. 4. This representation allows giving an overview of grid conditions on an annual base, but the temporal aspect is not depicted. Information on the simultaneity of voltage deviations and peak power on different phases and nodes is lost in such mode of representation.

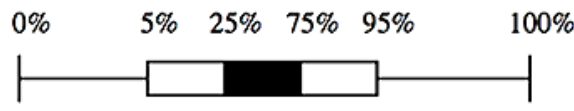

Fig. 4. Modified box plot.

The results for uncoordinated charging are illustrated in Fig. 5. The first column (Power Node) shows the distribution of the net power consumption at the node, taking household 
load, EV load and PV generation into account. Columns 2-4 (Voltage phase 1/2/3) illustrate the voltage distributions in each phase. The last column (Unbalance) depicts the VUF, considered as the ratio of the inverse to the direct component of the voltage phasor.

As can be seen, the voltages on each of the nodes and at each phase stay within the allowed band $( \pm 10 \%)$ around the nominal voltage for more than $95 \%$ of time. The VUF stays below the $2 \%$ limit for more than $95 \%$ of time. At the nodes that are located further away from the transformer, a small percentage of the simulations (less than $5 \%$ ) result in voltage deviations an VUFs exceeding the allowed band. Therefore, it is desirable that the peak shaving coordination algorithm will not increase the voltage deviations.

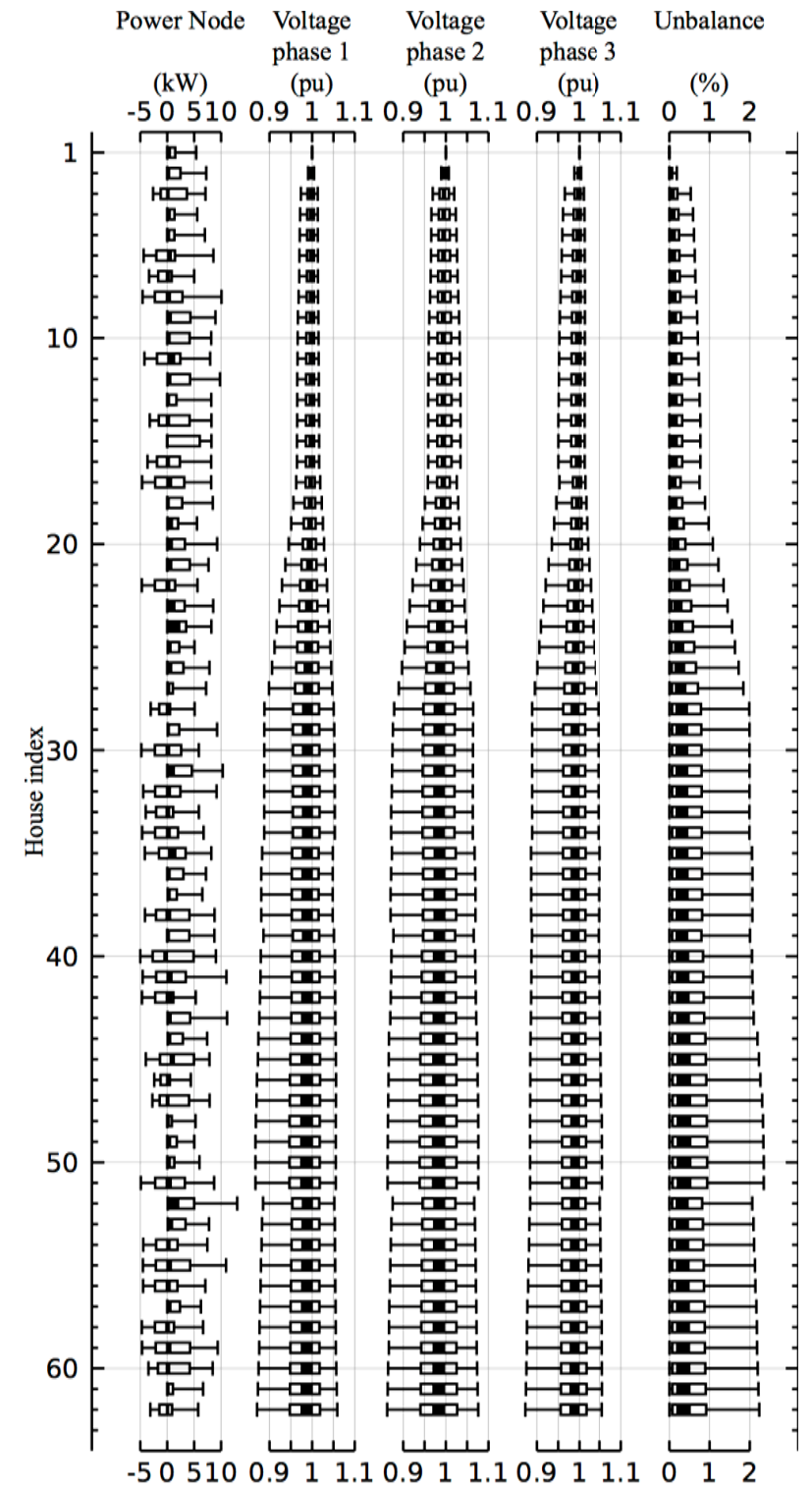

Fig. 5. Load flow results for uncoordinated charging.

\section{COORDINATION ALgORITHM}

In reality, perfect knowledge on driving behavior, household energy consumption and PV power production is not available. This non-aggregated information is highly stochastic and difficult to predict [21]. Furthermore, it is desirable that a practical coordination algorithm only needs a limited amount of communication, measurements and predictive knowledge, in order to have minimal local intelligence and allowing for a maximal responsiveness. Therefore, Intelligator is selected as a practical coordination algorithm.

\section{A. Intelligator}

Intelligator is a multi-agent market based demand side management algorithm inspired by PowerMatcher [23]. In Intelligator, every participant in a virtual power market is represented by an agent who places priority bids in this virtual market [22]. The agents represent the interests of the participants and ensure that local constraints are met: peak power rating, mobility behavior, etc. In the scenarios simulated in the work described here, all EVs are represented by an agent.

Also the non-flexible domestic load and production (PV) are represented by agents. An example of the hierarchic market as used in the simulations is illustrated in Fig. 6. All EVs are represented by their bid function. Bid functions of multiple EV agents are aggregated by an aggregator agent. At the top node in the hierarchical structure, the bid functions of all devices are aggregated, including those of the domestic loads and production profiles. The transformer is also represented by an agent and a clearing priority is determined based upon a balance between consumption and production. This clearing priority is sent back to all agents who consume or produce power according to the bid function value at the clearing priority [22].

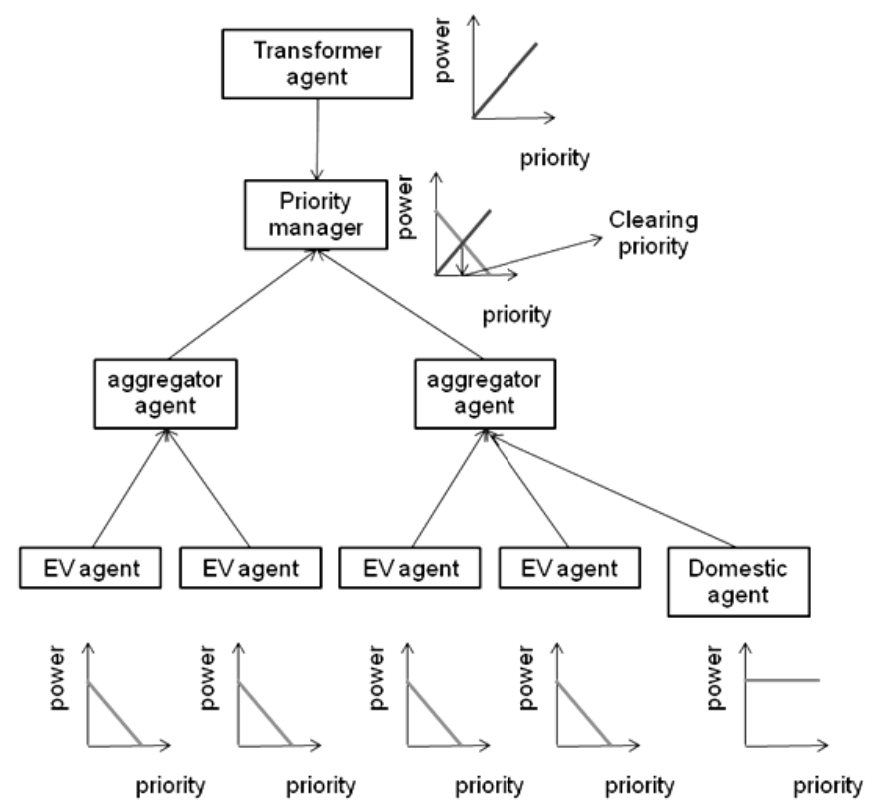

Fig. 6. Illustration of the market as used in the simulations.

The performance of the Intelligator coordination algorithm is strongly dependent on the logic used to define the priority bid functions of the different participants. These priorities have a similar function as prices have in typical markets, and can be regarded as a heuristic representing the necessity to consume power. In the simulations used here, the logic is kept very simple in order to have a minimal local intelligence and 
allowing for a maximal responsiveness. Generally speaking, the EV priority $\mathrm{P}_{\mathrm{r}}\left(\mathrm{E}_{\mathrm{t}}, \mathrm{t}\right)$ is calculated as:

$$
P_{r}\left(E_{t}, t\right)=\frac{t-t_{s}}{t_{f}\left(E_{t}, t_{d}, P\left(E_{t}\right)\right)-t_{s}}
$$

with $t_{s}$ the arrival time and $t_{f}\left(E_{t}, t_{d}, P\left(E_{t}\right)\right)$ the final moment at which charging has to start in order to have a fully charged battery at the departure time. Therefore, the departure time for the next trip is the only predictive knowledge that is used by Intelligator. The bid function for the EV is now defined as:

$$
b\left(P_{r}\right)=P(S O C) \cdot H\left(P_{r}\left(E_{t}, t\right)-P_{r}\right)
$$

with $\mathrm{H}$ the Heaviside step function. The peak shaving strategy is obtained by using a simple linear bid function for the transformer:

$$
b\left(P_{r}\right)=A P_{r}
$$

The slope A defines the amount of peak shaving and is matched for a certain peak power rating. In this case, the slope is matched to limit peak power demand to the peak value that occurs without EVs. The bid functions of the non-flexible domestic supply/demand are intrinsically constant values which correspond to the current production or consumption. Only a limited amount of data needs to be exchanged to perform the coordination. This reduces the communication overhead and the computational requirements needed to run the coordination algorithm.

\section{B. Peak Shaving}

The impact of the Intelligator coordination algorithm on peak power demand is illustrated in Fig. 7. As can be seen, the coordination algorithm is capable of avoiding an increase in peak power demand due to the EVs The flexibility of EVs, constraint to their mobility behavior, allows shifting charging in time in such a way that peak power demand will not increase due to the EVs.
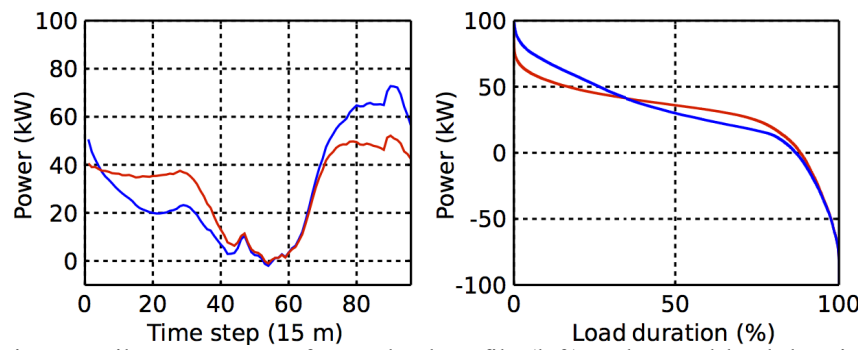

Fig. 7. Daily average transformer load profile (left) and annual load duration curve (right) for uncoordinated (blue) and coordinated (red) EV charging.

However, valley power demand around noon, created by PV power production, is not filled up through coordinated charging. As mentioned before, this is due to the weak correlation between EV mobility behavior and PV power production. Therefore, a negative power demand, due to a high amount of PV power production, is not to be avoided through coordinated charging. However, it must be emphasized that conclusions concerning the synergy between EV and PV are only valid for these specific assumptions, when vehicles are maximally charged before every next trip.
When using different assumptions for the coordination algorithm, the results may be different.

\section{Grid Impact Analysis}

The results for the coordinated charging scenario are illustrated in Fig. 8, which has a lay-out that is identical to Fig. 5. The nodal voltage deviations and VUFs at locations far away from the transformer are reduced compared to uncoordinated charging. This is due to the correlation between peak power demand and maximal voltage deviations.

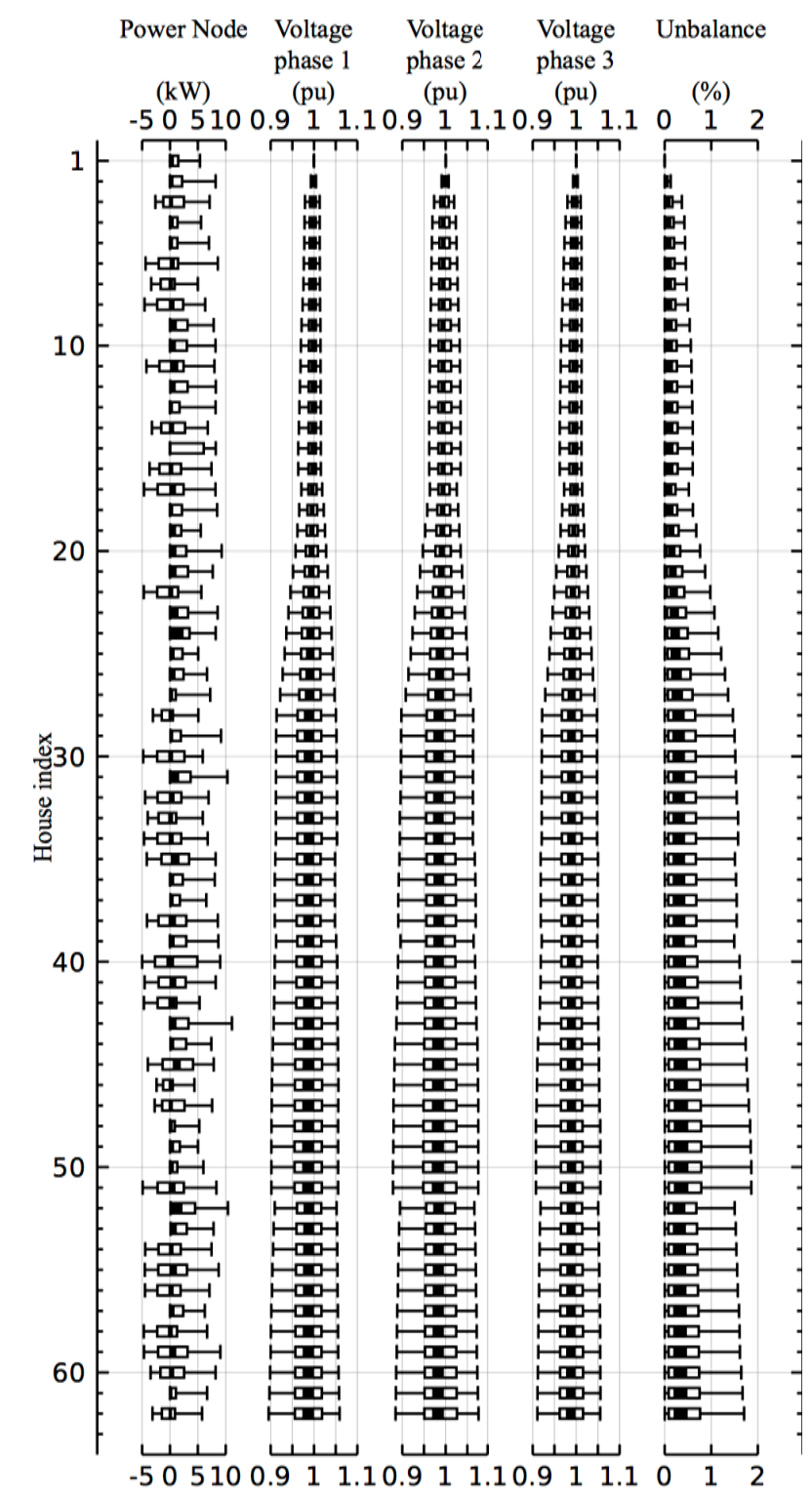

Fig. 8. Load flow analysis for coordinated charging.

The peak shaving objective for coordinated charging reduces the simultaneity of household and EV power demand. This will reduce the peak currents that run through the grid and thus also the resulting peak voltage deviations. This effect is considered as logical for a balanced situation, but the simulations show that this is also valid for the unbalanced load situation in a LV residential distribution grid.

The results indicate that coordinated charging, with a gridlevel peak shaving objective, will reduce the highest nodal voltage deviations. Thus, for a situation where nodal voltages 
are within limits for uncoordinated EV charging, coordination for a peak shaving objective will not create excessive voltage deviations. Implementing the peak shaving objective with Intelligator, in order to avoid an unneeded transformer upgrade, will not create an increase in voltage deviations or unbalance, which could create the need for cable upgrading. Therefore, Intelligator is effective in deferring grid infrastructure investments.

\section{CONCLUSIONS}

A peak shaving coordination algorithm is implemented for EV charging, using an online multi-agent market based demand side management algorithm, which only uses limited predictive knowledge (departure time for the next trip). The simulation results show that the algorithm is effective for the peak shaving objective, peak power demand is not increased compared to the situation without EVs. Therefore, the online coordination algorithm has a positive impact on transformer and cable aging, due to avoiding an increase in hot spot temperature.

The online coordination algorithm only requires a limited amount of data (transformer loading) and predictive knowledge (departure time for next trip). This reduces the communication overhead and the computational requirements needed to obtain a solution of the coordination algorithm. Also, no specific information on the LV grid (topology, cable parameters) is required, thereby making it widely applicable and also suited for unbalanced load conditions. These are considerable advantages for implementation of coordinated charging in the LV grid, because of the expansive size of the infrastructure and the diversity of grid topologies and parameters that are present in the power system.

Furthermore the coordination algorithm has a positive impact on the nodal voltage deviations and unbalance factors. The largest voltage deviations and unbalance factors, in the case of uncoordinated charging, are reduced through coordinated charging. Thus, the peak shaving objective does not cause new problems on other grid constraints. Therefore, using Intelligator for coordinated EV charging is effective in deferring grid infrastructure investments.

As a result, using an online coordination algorithm for $\mathrm{EV}$ charging, e.g. Intelligator, can be considered as an effective manner to make more efficient use of the distribution grid. The implementation of a coordination strategy in this way is compatible with the current distribution planning philosophy, namely to stay away from the limits as far as possible.

\section{REFERENCES}

[1] I. Michaeli, C. Reenock, D. Kapoor. (2011, Feb.). Electric Vehicles: Perspectives on a Growing Investment Theme. Citi Investment Research \& Analysis. Long Island City, NY. [Online]. Available: http://www.ceres.org/resources/reports/electricvehicles-report

[2] N. Tanaka. (2009, Jan.). Technology Roadmap: Electric and plugin hybrid electric vehicles. International Energy Agency. Paris, France. [Online]. Available: http://www.iea.org

[3] F.C. Boureima, J. Matheys, V. Wynen, N. Sergeant, J. Van Mierlo, M. Messagie, "Comparative LCA of Electric, Hybrid, LPG and Gasoline family cars in a Belgian context", World Electric Vehicle. J., vol. 3, 2009
[4] M. Duvall, E. Knipping. (2007, July). Environmental Assessment of Plug-In Hybrid Electric Vehicles. Electric Power Research Institute. Palo Alto, CA. [Online]. Available: http://my.epri.com

[5] K. Clement-Nyns, "Impact of plug-in hybrid electric vehicles on the electricity system", Ph.D. dissertation, Dept. Elect. Eng., KU Leuven, Leuven, Belgium, 2010

[6] E. Peeters, C. Develder, J. Das, J. Driesen, and R. Belmans, "LINEAR: towards a breakthrough of smart grids in flanders", Proc. 2nd Int. Conf. Innovation for Sustainable Production, vol. 3, Bruges, Belgium, 2010, pp. 3-6.

[7] N. Leemput, J. Van Roy, F. Geth, P. Tant, B. Claessens, J. Driesen, "Comparative Analysis of Coordination Strategies for Electric Vehicles.", IEEE PES ISGT Europe, Manchester, United Kingdom, Dec. 5-7, 2011

[8] G.T. Heydt, "The Impact of Electric Vehicle Deployment on Load Management Strategies," IEEE Trans. Power App. Syst., vol. PAS102, no. 5, pp. 12531259 , May 1983

[9] J. Van Roy, N. Leemput, S. De Breucker, F. Geth, P. Tant, J. Driesen, "An Availability Analysis and Energy Consumption Model for a Flemish Fleet of Electric Vehicles", European Electric Vehicle Congress (EEVC), Brussels, Belgium, October 26-28, 2011, 12 pages.

[10] A.S. Masoum, S. Deilami, P.S. Moses, A. Abu-Siada, "Impacts of battery charging rates of Plug-in Electric Vehicle on smart grid distribution systems", 2010 IEEE PES ISGT Europe, Gothenburg, Sweden, Oct. 11-13, 2010

[11] P. Papadopoulos, S. Skarvelis-Kazakos, I. Grau, L.M. Cipcigan, N. Jenkins, "Predicting Electric Vehicle impacts on residential distribution networks with Distributed Generation", 2010 IEEE Vehicle Power and Propulsion Conference (VPPC), Lille, France Sept. 1-3, 2010

[12] A. Franzen, S. Karlsson. (2007, Jan.). Failure Modes and Effects Analysis of Transformers. KTH Electrical Engineering. Stockholm, Sweden. [Online]. Available: eeweb01.ee.kth.se/upload/publications/reports/2007/TRITAEE_2007_040.pdf

[13] C. Farmer, P. Hines, J. Dowds, and S. Blumsack, "Modeling the Impact of Increasing PHEV Loads on the Distribution Infrastructure", 43rd Hawaii Int. Conf. System Sciences, pp. 1-10, 2010.

[14] IEEE Recommended practice for establishing transformer capability when supplying non sinusoidal load currents, IEEE Std. C57.110-2008 (revision of IEEE Std C57.110-1998), Aug. 2008

[15] Q. Gong, S. Midlam-Mohler, V. Marano, and G. Rizzoni, "Study of PEV Charging on Residential Distribution Transformer Life", IEEE Trans. Smart Grid, vol. 3, no. 1, pp. 404-412, March 2012

[16] C. Dang, J.-L. Parpal, J.-P. Crine, "Electrical aging of extruded dielectric cables: review of existing theories and data", IEEE Transactions on Dielect. Electric. Insul., vol. 3, no. 2, pp. 237-247, Apr. 1996

[17] L. Chmura, H. Jin, P. Cichecki, J.J. Smit, E. Gulski, F.D. Vries, "Use of dissipation factor for life consumption assessment and future life modeling of oil-filled high-voltage power cables", IEEE Electr. Insul. Mag., vol. 28, no. 1, pp. 27-37, Jan.-Feb. 2012

[18] M. Savaghebi, A. Jalilian, A. Gholami, "A new approach for transformer loading capability assessment under non-linear load currents", 2008 IEEE Int. Conf. Industrial Technology, Apr. 2008

[19] A. Franzen, L. Bertling. (2007, Aug.). State of the art- lifetime modeling and management of transformers. KTH Electrical Engineering. Stockholm, Sweden. [Online]. Available: eeweb01.ee.kth.se/upload/publications/reports/2007/TRITAEE_2007_041.pdf

[20] Voltage Characteristics of Electricity Supplied by Public Electricity Networks, CENELEC Std. EN 50 160, Jul. 2010

[21] H. L. Willis. "Power Distribution Planning Reference Book", New York: Marcel Dekker Inc., 1997

[22] M. Ghijsen, R. D'Hulst, "Market-based coordinated charging of electric vehicles on the low-voltage distribution grid", IEEE First International Workshop on Digital Object Identifier: Smart Grid Modeling and Simulation (SGMS), pp. 1-6, 2011

[23] Kabels Voor Ondergrondse Aanleg, met Synthetische Isolatie en Versterkte Mantel (Type 1kV), NBN Std. C 33-322, 1975

[24] Specifieke Technische Voorschriften Voor Decentrale ProductieInstallaties die in Parallel Werken met het Distributienet, Synergrid regulation C10/11, Rev. 12, May 2009. 
[25] M.P.F. Hommelberg, C.J. Warmer, I.G. Kamphuis, J.K. Kok, G.J. Schaeffer, "Distributed control concepts using Multi Agent technology and automatic markets: an indispensable feature of smart power grids", IEEE Power Engineering Society General Meeting, pp. 1-7, June 2007

\section{BIOGRAPHIES}

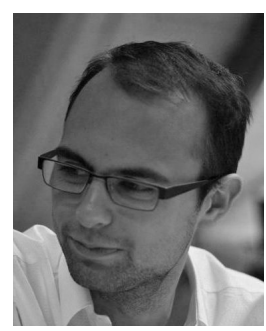

Niels Leemput ( $\left.\mathrm{S}^{\prime} 11\right)$ received the M.Sc. degree in Electrical Engineering, with specialization in energy, from the KU Leuven, Belgium, in 2010, where he is currently working towards the Ph.D. Degree, funded by IWT-Vlaanderen.

Currently, he is working as a research assistant with the division ESAT-ELECTA. His research interests include the grid integration of charging infrastructure for electric vehicles and power electronics for gridcoupling of electrical vehicles.

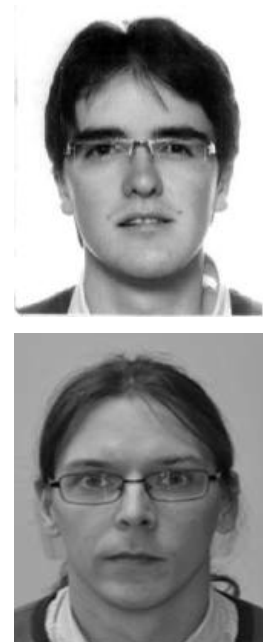

Frederik Geth (S'10) received the M.Sc. degree in electrical engineering from the KU Leuven, Belgium, in 2009.

Currently, he is working as a research assistant with the division ESAT-ELECTA. His research interests include optimal storage integration in distribution grids, batteries for (hybrid) electrical vehicles and controlling the impact of the charging currents of (hybrid) electrical vehicles on the grid.

Bert Claessens obtained his $\mathrm{MSc}$. and $\mathrm{PhD}$. in applied physics from the University of Technology of Eindhoven, The Netherlands, in 2002 and 2006, respectively. In 2006 he started working at ASML Veldhoven, The Netherlands, as a design engineer. Since June 2010 he has been working as a researcher at the Vlaamse Instelling voor Technologisch Onderzoek (VITO). His research interests are in algorithm development and data analysis

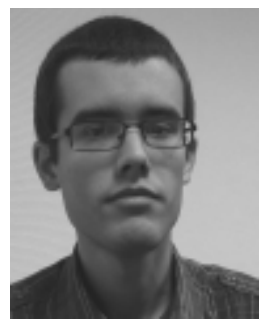

Juan Van Roy (S'09) received the M.Sc. degree in Electrical Engineering, with specialization in energy, from the KU Leuven, Belgium, in 2010, where he is currently working towards the Ph.D. degree.

Currently, he is working as a research assistant with the division ESAT-ELECTA. His research interests include controlling the impact of the charging of (hybrid) electric vehicles on the grid and the integration and interaction of different energy flows and networks (electrical and thermal) in buildings.

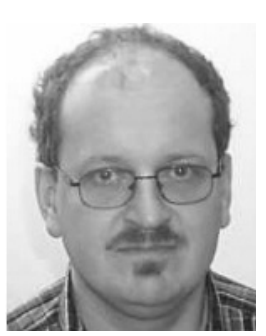

Raf Ponnette obtained his degree of master in electromechanical engineering in 1989 at the University of Brussels. At VITO he is responsible for the Sustainable Grid Connected Vehicles \& Infrastructure research program. This program focuses on the research and development of smart systems that enable the integration of electric vehicles as an active component in a smart grid. These systems will allow to add more distributed renewable energy sources to the electricity system.

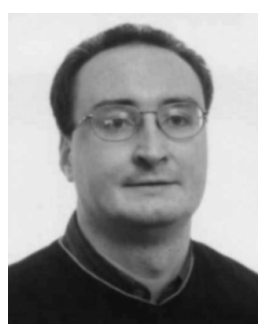

Johan Driesen (S'93 - M'97 - SM'12) received the M.Sc. and Ph.D. degrees in Electrical Engineering from the KU Leuven, Belgium, in 1996 and 2000 , respectively.

Currently, he is a Professor with the KU Leuven and teaches power electronics and electric drives. In 2000, he was with the Imperial College of Science, Technology and Medicine, London, U.K. In 2002, he was with the University of California, Berkeley.

Currently, he conducts research on distributed generation, power electronics, and its applications. 